\title{
Circunvalaciones de la muerte. Beckett-Derrida-Poe
}

\author{
Gabriela García Hubard
}

\begin{abstract}
Tomando como hilo conductor la posibilidad y/o la imposibilidad de vivir la propia muerte, la primera parte de este texto explora las coincidencias entre algunas aporías en los textos de Samuel Beckett y de Jacques Derrida; vinculando muerte y escritura, la aporía no se presenta como un simple impasse, sino como agonía, es decir, como una lucha. Continuando con la tensión entre muerte y escritura, la segunda parte del texto indaga sobre la contaminación y los ecos que produce la obra de Edgar Allan Poe en algunos textos de Jacques Derrida; la relación entre escritura, muerte e hipnosis parece desestabilizar la frontera que separa y une a la literatura y a la filosofía.
\end{abstract}

Palabras clave: Beckett, Derrida, muerte y escritura.

Bearing in mind, as the main thematic line, the possibility and/or impossibility of living one's death, the first part of this paper explores the similarities between some aporias in the texts of Samuel Beckett and Jacques Derrida; relating then death and writing, aporia is not presented as a simple impasse but as agony, as struggle. Following the tension between death and writing, the second part of the text inquires into the contamination produced by Edgar Allan Poe's work in some of Derrida's texts; the relationship between writing, death and hypnosis seems to undermine the boundary that separates and brings together literature and philosophy.

KeY wORDS: Beckett, Derrida, death and writing.

Fecha de recepción: 12 de marzo de 2010

Fecha de aceptación: 5 de agosto de 2010 

Gabriela García Hubard

Universidad Nacional Autónoma de México

\title{
Circunvalaciones de la muerte. Beckett-Derrida-Poe
}

\begin{abstract}
¿Dónde situar el sintagma "mi muerte" como posibilidad y/o imposibilidad del pasar? (la barra móvil entre $\mathrm{y} / \mathrm{o}, \mathrm{y} / \mathrm{y}$ o/y o/o, es una frontera singular - lo vamos a ver- a la vez conjuntiva, disyuntiva o indecidible).
\end{abstract}

JACQUES DERRIDA

La muerte es sin duda uno de los temas más recurrentes en diversas disciplinas, dentro de las cuales la literatura y la filosofía ocupan un lugar incuestionable. Dentro de este tema tan vasto e inagotable podemos reconocer otra línea, o "barra móvil", entre la muerte en general y la propia muerte. Es pues a partir del sintagma "mi muerte", el cual "relaciona aquí lo posible con lo imposible" (Derrida, Résistances de la psychanalyse, 48), como me gustaría comenzar esta lectura sobre las aporías de la muerte y su relación con la escritura.

La palabra "aporía" proviene del griego a-póros, literalmente sin paso, y el término se aplica principalmente a aquellos lugares difíciles de cruzar, o incluso intransitables, como los mares y los océanos. En su forma más común, la aporía repre- 
senta el callejón sin salida, por lo que en la filosofía moderna se identifica con una dificultad lógica insuperable. Sin embargo, como lo muestra Rodolphe Gasché (2002), el estatus de la aporía no se puede reducir, si pensamos en los griegos, a un simple impasse o camino bloqueado. Si para los escépticos la aporía es el único tema posible de todo esfuerzo filosófico, si para Platón designa la pausa del razonamiento filosófico que está comprometido con el camino de la verdad, y para Aristóteles es el método de investigación que parte de opiniones opuestas, nos encontramos entonces frente a un abanico de posibilidades aporéticas que se encuentran muy lejos de la simple negación del camino. ${ }^{1}$

Dentro de este abanico de posibilidades que va más allá de los griegos, me gustaría delinear algunos paralelos entre las aporías beckettianas y derridianas - las cuales conllevan las huellas de Heidegger y Poe- - para subrayar algunas coincidencias sin borrar sus diferencias.

La vieja idea filosófica de no poder vivir la propia muerte es evocada en la obra de Samuel Beckett desde Eleutheria en los años cincuenta: "Si yo estuviera muerto [dice Víctor], no sabría que estoy muerto. Es lo único que tengo contra la muerte" (146). Vieja imposibilidad que encontramos de nuevo en Malone Muere — segundo libro de la Trilogía - cuando el narrador admite: "No me miraré morir, eso lo falsearía todo" (8. Traducción modificada), reconociendo así la imposibilidad de vivir la propia muerte; si Malone muere, como lo sugiere el título de la obra, ya no estará ahí para mirarse.

Pero esta imposibilidad de vivir la propia muerte adquiere otra dimensión, dos páginas más adelante, cuando el narrador

${ }^{1}$ Es por esto que Gasché nos dice que "confrontados con la aporía debemos encontrar un poros", es decir "un camino para salir de la situación difícil e intolerable. Y por lo mismo, un poros no es cualquier camino" ("L'experience aporétique", 107). Las traducciones del francés al español son mías, salvo aquellas que aparecen en español en la bibliografía. 
confunde la posibilidad y/o la imposibilidad de vivir la propia muerte con la escritura: "Durante la noche he tenido que reflexionar sobre mi empleo del tiempo. Creo que podré contarme cuatro historias, cada una sobre un tema distinto [...] Es posible que no tenga tiempo para terminar. Por otro lado, tal vez termine demasiado pronto. Heme aquí de nuevo en mis viejas aporías" (10). En la versión original en francés, la confusión entre escritura y muerte, entre terminar y morir, es más clara: "Peut-être que je n'aurai pas le temps de finir. D'un autre côté, je finirai peut-être trop tôt. Mais/Me voilà à nouveau dans mes vieilles apories" (10). Mostrando una fuerte ambivalencia con respecto a "terminar" (finir), el narrador pone en marcha el juego de la indecisión que relaciona la muerte y la escritura. Es así como el narrador está frente a la posibilidad y/o imposibilidad de terminar de contar sus historias, la cual se confunde con la posibilidad y/o imposibilidad de morir, finir, terminar. Esta ambivalencia en torno a la palabra "finir", entendida como "terminar" o como "morir", esta doble paradoja que podríamos parafrasear de la siguiente manera: terminar es no terminar, puesto que terminando uno no termina, este doble juego — que en sí se vuelve a desdoblar — es al que el narrador llama "viejas aporías".

Ante esta posibilidad y/o imposibilidad de la propia muerte y de la propia escritura, pero sobre todo de la propia muerte, resulta inevitable pensar en Heidegger quien, en un momento dado, nos dice que "la muerte es la posibilidad de la absoluta imposibilidad del 'ser ahí'" (El ser y el tiempo, 274). Los ecos heideggerianos que podemos encontrar en la obra de Beckett - muchos de ellos con una alta dosis de ironía- no son pocos, sin embargo, me gustaría detenerme un instante en esta idea de la propia muerte como la posibilidad de la imposibilidad y su relación con la escritura. Mientras que el juego beckettiano en torno al "finir" (terminar) le permite a Malone acercarse, a través de la escritura, a su propia muerte $-\mathrm{y}$ a la muerte en 
general-, también conlleva el riesgo de destruir muy pronto - trop tôt, como lo dice el narrador - toda posibilidad de escritura puesto que puede morir; si Malone muere no podrá continuar con sus historias.

Es justo en este punto donde podemos encontrar una fuerte coincidencia entre las aporías de Malone y la aporía que Derrida pone en evidencia cuando muestra la manera en que el " "fin' amenaza y torna posible la analítica" existencial de Heidegger (Derrida, Aporías, 129). En su libro Aporías, Derrida sostiene que no podemos asegurar las fronteras cuando hablamos de la muerte, e insiste en que la delimitación que Heidegger establece en El ser y el tiempo entre la muerte del Dasein y las otras formas de terminar o perecer, es problemática desde el momento en que se establece una jerarquía - con principio y fin - sobre los distintos modos de morir. Sin embargo, como es de Beckett y Derrida de quienes estoy hablando, no me voy a detener en las aporías heideggerianas. Retengamos por el momento esta idea del finir, morir, terminar, como aquello que amenaza y hace posible el "análisis" y la escritura.

En esta tensión entre la escritura y la muerte reconocemos el temor de morir antes de terminar de escribir. Mientras Malone se pregunta si no tendrá tiempo de terminar o si terminará demasiado pronto, también reconoce que ignora el momento preciso de su propia muerte y, por ende, cuál será su última palabra escrita. Este miedo, que es quizás tan viejo como la aporía, amenaza constantemente la escritura derridiana: "otra vez miedo de morir antes de haber terminado mi frase", leemos en los envíos de La tarjeta postal (53). Pero es en su texto "Circonfession", en el cual Derrida escribe sobre la agonía de su madre, en donde este temor, que pareciera multiplicarse, adquiere mayor relevancia:

el miedo que tengo desde siempre, pues al menos a eso soy fiel, se disloca, se encuentra amenazado por dos inminencias 
aparentemente contradictorias, la del escritor que teme morirse antes del fin de una larga frase, eso es todo, sin firmar ningún contra-ejemplo, y la del hijo que temiendo verla morir antes del fin de la confidencia, por esta confesión que se promete a la muerte, tiembla pues, así mismo, de marcharse antes que su madre (52). ${ }^{2}$

Me parece importante resaltar varios aspectos de este fragmento. Por un lado, podemos reconocer que, al igual que en $\mathrm{Ma}$ lone Muere, en este texto el "fin" — o más bien la lucha con el "finir" - amenaza y torna posible la escritura. Si la madre muere, se termina la "confesión" sobre la agonía, pues este es el tema (o uno de los temas principales) del texto. Por el otro lado, estamos por lo menos frente a tres miedos: el temor de morir antes de terminar la frase, que va de la mano con el miedo de ver morir a la madre antes de terminar la confesión, pero también con el temor de morir antes que la madre: "si yo muero antes que mi madre" (91), "esperando morir antes que la madre" (103), escribe una y otra vez Derrida.

Ahora bien, siete u ocho años antes de la publicación de "Circonfession", Derrida escribió "Mes Chances". En este texto aborda —entre otros temas - el último capítulo del libro

2 "la peur qui me tient depuis toujours, car à cela du moins je suis fidèle, se désaccorde, elle se menace depuis deux imminences apparemment contradictoires, celle de l'écrivain qui craint de mourir avant la fin d'une longue phrase, un point c'est tout, sans signer le contre-exemple, et celle du fils qui, redoutant de la voir mourir avant la fin de l'aveu, pour cette confession promise à la mort, tremble donc aussi de partir avant sa mère" (52). Resulta interesante señalar que en esta misma página en donde el filósofo "confiesa" estos miedos ante la muerte, Geoffrey Bennington, en su texto titulado "Derridabase" y que acompaña el texto de Derrida de una manera poco usual, escribe: "Ce qu'on appelle ici 'mort' est le nom générique qu'on donnera à mon absence en général par rapport à ce que j'écris" (52). A esta relación entre la muerte y la ausencia, con respecto a la escritura, regresaremos más adelante. 
de Freud, Psicopatología, en donde el padre del psicoanálisis cuenta la tan mencionada historia de la anciana que era su paciente y a quien tenía que visitar, no sin antes llegar a una dirección equivocada por error del chofer. Recordando ese texto que evoca la muerte de la anciana ese mismo año y que explora temas como la creencia, el azar y la superstición, Derrida escribe:

Parece que Freud excluye rápidamente cualquier comunicación entre el inconsciente del que conduce y el suyo propio. Siguiendo entonces mi propia compulsión [hermenéutica], me dije súbitamente: “¿y si esa anciana fuera la madre de Freud?” Ya saben cuánto temía Freud la muerte de su madre, efectivamente, pero también temía morir antes que ella: double bind (37). ${ }^{3}$

Este temor de la muerte de la madre que pareciera espejearse con el temor de morir antes que ella - tema que también encontramos en la trilogía de Beckett— es, en palabras del filósofo, un double bind.

El double bind, como bien sabemos, es un gesto doble y contradictorio que tiene una historia compleja en la psiquiatría, pero también en los estudios lingüísticos. Sin embargo, me voy a limitar a recordar que, en Resistencias del psicoanálisis, Derrida nos dice que el double bind determina la experiencia de la aporía y sin ellos no habría evento (52). Lógicamente tendríamos que preguntarnos: ¿qué puede significar el hecho de que el double bind determine la aporía?, ¿la precisa, la limita, la reconoce, la regula, la causa o la produce, le permite ser? Ese gesto contradictorio, sutil y agudo, que une y separa al mismo

3 "Freud semble exclure bien vite toute communication entre l'inconscient de celui qui le conduisait et le sien propre. Suivant alors ma propre compulsion [herméneutique], je me suis dit brusquement: 'et si cette vieille dame était la mère de Freud?' Vous savez combien il redoutait la mort de sa mère, certes, mais craignait aussi de mourir avant elle: double bind" (37). 
tiempo, es un gesto doble, y en la palabra doble identificamos una multiplicación, puesto que no hablamos de un gesto o de un simple gesto, sino de un doble gesto. En esta dirección, podemos decir que lo que preceda, pero también lo que procede de la aporía en la obra del filósofo, es siempre plural, puesto que pluralizar significa, para Derrida, "otorgarse siempre una salida de emergencia” (Aporías, 39). Precisamente esto es lo que hace nuestro autor frente a la aporía de la muerte: pluralizarla. Basta hacer referencia a algunos títulos de sus textos: "Las muertes de Roland Barthes", Aporías, Memorias para Paul de Man, Espectros de Marx, 'et caetera', todos ellos en plural.

Es justamente a través de esta coyuntura entre el double bind y la aporía como podemos regresar a las viejas aporías de Malone, puesto que estas tensiones y estos temores en torno a la muerte, en las obras de Beckett y Derrida, parecen llevarnos por un camino similar y, por paradójico que sea - puesto que estamos hablando de aporía, es decir, de la ausencia de camino-- ese camino o esos caminos paralelos, son justamente las aporías. Finalmente, tanto en Malone Muere como en "Circonfession", estamos frente a una contaminación entre la agonía de la muerte y la agonía de escribir. Entre ellas, la aporía como fin, muerte, pérdida, límite o contradicción, también se presenta como una lucha; la aporía es un combate que esboza un pensamiento, que no puede ser ni simplemente literario, ni puramente filosófico.

Pero esta relación entre escritura y muerte aún tiene mucho que decirnos. Desde los años sesenta, en La voz y el fenómeno, uno de los textos más decisivos en la obra de Derrida, la importancia que éste confiere a la muerte como la condición de la posibilidad del lenguaje y de la escritura, se ve más que ejemplificada, contaminada con el epígrafe de "La verdad sobre el caso del señor Valdemar" de Edgar Allan Poe. En ese texto, donde el filósofo deconstruye algunos puntos claves de la fenomenología de Husserl, no dejan de sorprendernos las 
referencias a Poe. El hecho de que Derrida "empieza" su libro con dos epígrafes de Husserl, quien buscaba una objetividad científica, y las palabras del señor Valdemar "-Ahora estoy muerto", permite aventurar la lectura de esos ecos en la obra del filósofo que, desde mi parecer, no han sido lo suficientemente explorados.

Pero detengámonos un instante en la obra de Poe. Aquello que Julio Cortázar llamó "el lado anormalmente sádico y necrofílico del genio de Poe" (Poe, Cuentos I, 31), engendra un repertorio que pareciera inigualable. Tan sólo pensemos en las pinceladas que roban la vida de la amada en "El retrato oval", en las innumerables muertes por enfermedades o epidemias como en "La máscara de la Muerte Roja" o, más aún, en los supuestos "crímenes" cometidos por un orangután en "Los crímenes de la Calle Morgue". ¿Cómo olvidar la confusión entre la vida y la muerte en los entierros prematuros y "La caída de la Casa Usher"? Entramos a un mundo, minuciosamente descrito, de manchas escarlata, de cadáveres que se mueven y recobran vida y en donde sólo "en la muerte se mide la fuerza del afecto", como en "Ligeia": "la amada, la augusta, la hermosa, la enterrada" (310).

Sin embargo, frente a este universo mortuorio y más allá de toda la fantasía, lo extraordinario, el terror, lo absurdo, lo macabro, lo mórbido y lo sobrenatural, quisiera destacar la manera como la posibilidad y/o la imposibilidad de vivir la propia muerte juega un papel importante en su obra: "Los límites que separan la Vida y la Muerte son, en el mejor de los casos, vagos e indefinidos. ¿Quién puede decir dónde termina una y dónde empieza la otra?", nos dice el narrador de "El entierro prematuro" (194). Entre las innumerables experiencias mortuorias en la obra de Poe encontramos, por un lado, enfermos y, por el otro, muertos vivientes, fantasmas o espectros; pero son pocos los relatos que se detienen en esa frontera que separa la vida y la muerte. Revisando la obra del escritor podemos mencionar 
- hasta el momento - tres relatos: "Un cuento de las Montañas Escabrosas", "La verdad sobre el caso del señor Valdemar" y "Revelación mesmérica", destacando la manera en que, en estos tres cuentos, la posibilidad y/o imposibilidad de vivir la propia muerte parece indisociable del mesmerismo o del hipnotismo - los cuales hasta finales del siglo XIX eran prácticamente sinónimos-: "Si estuviera despierto", dice el personaje de "Revelación mesmérica", "me gustaría morir, pero ahora no tiene importancia. El estado mesmérico se avecina lo bastante a la muerte como para satisfacerme" (341). Sueño, muerte, hipnosis; este parentesco tiene una historia más antigua en la mitología: Hipnos, no solamente es el dios del sueño, sino que es el hermano gemelo de Tánatos, dios de la muerte.

Resulta fascinante comprobar que en "Marginalia I", Poe se ocupa de las repercusiones que 'La verdad sobre el caso del señor Valdemar' tuvo en Londres, donde fue tomado por un informe científico" (Cortázar apud Poe, Cuentos II, 493), lo cual se explica por el hecho de que el mesmerismo y el hipnotismo estaban en pleno auge y generaban un gran interés en la época. Pero si pensamos hoy en día en el hipnotismo nos damos cuenta que estamos frente a otra frontera inestable, ¿no es acaso una práctica que oscila, y ha oscilado siempre, entre el ocultismo, la terapia, el espectáculo y la ciencia? Cortázar señala que Poe se familiarizó con el tema a través de una abundante bibliografía y asistiendo a conferencias de "magos", pero también agrega que el autor nunca aceptó los principios del mesmerismo, aunque los usaba con una gran destreza (506-509). Es así como, de manera extraña e irónica, el autor nos coloca entre tres (o más) fronteras frágiles y misteriosas: el sueño, la muerte y la hipnosis.

Ahora bien, lo que me parece importante señalar es la manera como las palabras del epígrafe en el libro de Derrida (“- - Sí... No... Estuve durmiendo... y ahora... ahora... estoy muerto") son indisociables del hipnotismo, de hecho son "pronunciadas" 
bajo el efecto hipnótico en el cuento de Poe (123-124). Aun cuando en los ejemplos de La voz y el fenómeno "mi muerte" puede ser el nombre genérico que damos a "mi ausencia" en general en relación a lo que escribo, como lo dice Bennington ("Derridabase", 52), tanto la preferencia del filósofo por hablar de la muerte, como sus referencias a Poe y la huella de la hipnosis, rompen con lo que podría convertirse en la simple contraposición presencia/ausencia, vida/muerte. El narrador de Valdemar es ese "intruso" al que Derrida invita, no de manera gratuita, para desestabilizar la frontera que separa y une la literatura, la filosofía y más allá, como lo veremos en un momento.

Pero antes quisiera recordar algunos de los puntos de $\mathrm{La} \mathrm{voz}$ y el fenómeno. Cuando enunciamos la expresión "yo soy", nos dice Derrida, para que ésta sea entendida, tiene que serlo "en ausencia del objeto, de la presencia intuitiva, por consiguiente, aquí, de mí mismo" (157). Cuando ustedes leen o escuchan "yo soy", entienden la expresión más allá de si me conocen, me ven o estoy viva.

Para comprender un enunciado de percepción no necesitamos percibir, de esta misma manera no necesitamos conocer a la persona que dice o escribe "yo" para comprender la palabra "yo". Es por esto que el filósofo señala que comprendemos la palabra "yo" aun cuando el "autor" es ficticio o está muerto. Si percibimos en el momento en que decimos un enunciado de percepción, o si estamos vivos y presentes cuando decimos "yo", no tiene mayor importancia en el funcionamiento del lenguaje. "Mi muerte [concluye Derrida] es estructuralmente necesaria al funcionamiento del $Y o$ [...] Y esta estructura está activa, guarda su eficacia original incluso cuando digo 'yo estoy vivo' [...] El enunciado 'yo estoy vivo' acompaña mi estar-muerto y su posibilidad requiere la posibilidad de que esté muerto; e inversamente. No es esto una historia extraordinaria de Poe, sino la historia ordinaria del lenguaje" (158). 
A partir de lo expuesto entendemos que un signo puede repetirse en la ausencia del sujeto que lo emite, pero también en la ausencia del receptor específico. Curiosamente ese posible y/o imposible receptor es el que parece tomar especial relevancia en su texto "Télépathie", uno de los envíos que debía aparecer en La tarjeta postal, y en donde leemos: "l'hypnose, c'est toi" (Derrida, "Télépathie", 258), "la hipnosis, eres tú." No resulta extraño que La tarjeta postal sea el libro de Derrida que más veces evoca la hipnosis. En un primer momento esta cita podría reforzar la hipótesis de la relación muerte-ausencia, ya que desde el prólogo leemos: “¿Quién escribe? ¿A quién? ¿Y para enviar, destinar, expedir qué? ¿A qué dirección? [...] finalmente no lo sé" (15), confiesa el filósofo.

Es en esas cartas o envíos en donde el "autor" borra todo lo que permite identificar la destinación: adestination nos dice el filósofo en donde la "a" privativa nos recuerda la "a" de a-póros - en dónde entendemos los ecos de: sin destinación o destino y sin camino-, en esos envíos la palabra hipnosis aparece en varias ocasiones, transformando una y otra vez sus posibles lecturas: "Multipliqué los trayectos, es como si escribiera bajo hipnosis" (149), y un poco más adelante: "No sé si la hipnosis ocurre cuando me voy o cuando vengo (tranquilízame, ¿no puede ser ambas cosas a la vez, verdad?), y si lo que llamo letargo de escritura ocurre cuando escribo o cuando no escribo, cuando te escribo a ti o no a ti" (150), finalmente el posible "autor" de los envíos confiesa escribir bajo hipnosis. Éstas son tan sólo algunas citas de La tarjeta postal en donde podemos entender la hipnosis como sueño, muerte, ausencia, incertidumbre, sugestión, entre otras, todas ellas relacionadas, directa o indirectamente, con la escritura.

Pero la hipnosis no significa una simple ausencia, no es un sinónimo de muerte - aunque se avecine a ella como en la obra de Poe o tenga un parentesco con ella en la mitología-, y en la obra del filósofo la hipnosis tiene una historia más rica y 
compleja que nos lleva más allá de una simple relación entre la literatura y la filosofía, es decir al psicoanálisis.

Aun cuando desde La tarjeta postal se establece una fuerte relación entre la hipnosis y el psicoanálisis, es en Resistencias del psicoanálisis donde, hablando de los sueños según Freud y del nudo de los sueños que resiste al análisis, Derrida sugiere que habría que tomar en cuenta el hecho de que el psicoanálisis comenzó a través del análisis de una resistencia a la sugestión hipnótica, y que esa resistencia legítima era insuperable (30).

A partir de este texto reconocemos que aquello que une $-\mathrm{y}$ por ende separa - la hipnosis, el psicoanálisis, la deconstrucción, y habría que agregar la literatura, son, por un lado, la compulsión a la repetición, la cual, como bien sabemos, está íntimamente relacionada con la pulsión de muerte en "Más allá del principio del placer" y, por el otro lado, a las resistencias. Ante las preguntas, ¿cómo podemos leer en la obra de Derrida el epígrafe que cita el texto de Poe? - y aquí entra en juego todo el trabajo sobre la citación en su obra-, ¿qué papeles juegan en La voz y el fenómeno - y prospectivamente en su obra - aquella voz bajo hipnosis que destaca la posibilidad y/o la imposibilidad de vivir la propia muerte?, tendríamos que reconocer el papel que desempeña ya no sólo la muerte sino también las resistencias en aquello que el filósofo llama "la historia ordinaria del lenguaje" y que no es una historia extraordinaria de Poe. Pareciera entonces que son precisamente algunas resistencias — resistencias a la significación, por ejemplo — las que nos impiden, por el momento, ir más lejos.

Pero lo que sí podemos decir para concluir es que la muerte de la que habla Derrida no es un simple contrapeso a la presencia metafísica. A través de la muerte radicaliza, por un lado, la importancia de la ausencia y, por el otro, escapa a las dicotomías, gracias a que los límites que separan la vida y la muerte, como bien lo dijo Poe, son vagos e indefinidos. Es así como, desde el epígrafe de Poe en La voz y el fenómeno, empezamos 
a percibir el papel que juega no sólo la muerte, sino la relación muerte-hipnosis en la obra del filósofo, la cual complica y enriquece de manera poco sutil todo su trabajo.

Si es verdad que no podemos delimitar claramente las fronteras en relación con la muerte, ¿cómo podemos entonces discernir las aporías de la muerte que van de la filosofía a la literatura, viceversa, y más allá?

\section{REFERENCIAS}

Beckett, Samuel, Malone Muere [1951], trad. Ana María Moix, Madrid, Alianza, 1997.

—, Eleutheria, París, Minuit, 1995.

Bennington, Geoffrey, "Derridabase", en Jacques Derrida, París, Seuil, 1991.

Derrida, Jacques, La voz y el fenómeno [1967], trad. Patricio Peñalver, Valencia, Pre-Textos, 1995.

_- La tarjeta postal [1980], trad. Haydée Silva, México, Siglo XXI, $2^{\text {a }}$ edición aumentada, 2001.

__, "Télépathie", en Psyché-Inventions de l'autre, París, Galilée, 1987-1998, 237-270.

_- "Mes chances", Cahiers Confrontation 19, París, Aubier-Montaigne, Printemps 1988, 19-45.

__, "Circonfession", en Jacques Derrida, París, Seuil, 1991.

—_, Résistances de la psychanalyse, París, Galilée, 1996.

—_, Aporías [1996], trad. Cristina de Peretti, Barcelona, Paidós, 1998.

GASCHÉ, Rodolphe, "L'expérience aporétique aux origines de la pensée: Platon, Heidegger, Derrida", trad. Georges Leroux, en Études Françaises 38.1-2.

—_, "Derrida Lecteur", Ginette Michaud y Georges Leroux ed., Montreal, Les Presses del'Université de Montréal, 2002, 103-21.

HeidegGer, Martin, El ser y el tiempo [1927], trad. José Gaos, México, Fondo de Cultura Económica, 2005.

Poe, Edgar Allan, Cuentos I y II [1956], prol., trad. y notas Julio Cortázar, Madrid-México, Alianza Editorial, 1992. 